\title{
The Renaissance Concept of Space: Notes on the Interaction between Arts and Sciences in History
}

\author{
Rein Undusk \\ Under and Tuglas Literature Centre of the \\ Estonian Academy of Sciences \\ Roosikrantsi 6, \\ Tallinn 10119, Estonia \\ E-mail: rein@utkk.ee
}

\begin{abstract}
The "Renaissance concept of space" harbors surely some definite bonuses for anybody embarking on a study of the inventive role that philosophy has had, in its happiest moments of life, for human cognition. First, the new suppositions related to physical space emerge in the Renaissance as derivative from the theological-philosophical assumptions of the era: what Renaissance space is can be enunciated quite convincingly on the basis of the intellectual collisions that the era was allotted to deal with. Thus, as a re-generator of classical culture, the Renaissance had to a degree dug up the finite substructure of ancient thinking; however, as an inheritor of the Middle Ages, it had been requested to square finitism with transcendency. Second, much of what we can today fit under Renaissance space is in fact delivered to us in the artistic form of painting, which means that, in addition to the challenge set by philosophy to the spatial knowledge of the era, there was postulated as well a mediatory agency of art in the realization and conveyance of this new knowledge. Thus we can suppose that the solution offered by Renaissance art to the problem of space on its fictional plane comprised the germ of some modern knowledge about space in reality.
\end{abstract}

Keywords: fiction, infinity, knowledge, non-Euclidean geometry, space 


\section{The cognitive dilemma of the Renaissance}

The aim of the following paper is to focus on the Renaissance construction of space as an excellent specimen for tackling the role of fictionality in the production of knowledge. The case promises to be still more interesting because it offers a fine historical example of how the impulses originating primarily in the religious context had impelled, in the quest for their scientific equivalents in our experience, a myriad of excellent pieces of art, where the aesthetic enjoyment, in its contemporary sense of the word, was underpinned by some great efforts at apprehending the world. ${ }^{1}$ The type of universal man, uomo universale, produced by the Renaissance is surely an expression of this interference of different cognitive demands (Kristeller, 1990, p. 44).

The so-called double historical inheritance of Renaissance culture provides us with a suitable point of departure. Defined in terms of rebirth of ancient culture and of humanism, the Renaissance could surely be said to have picked up to a degree the ancient outlook of space, which was characterized in some of its core principles by a tendency to reduce the content of space to the interrelationships of bodies. When asked, for example, how Aristotle conceived of place, we should say that he holds the place of a body to be an outer limit or exterior boundary of another, encompassing body. ${ }^{2}$ That is, for Aristotle space is not something that could be separated from bodily existence and could be claimed to have an independent quality, but rather space is something whose existence is concomitant and derived from the bodies phrasing the world. The

The fact that the idea of a unified systematic space (see Panofsky, 1997, pp. 42-43, 58), revealing itself around the Renaissance, was largely conceived out of exigencies imposed by Christian monotheism on the human mind (as to postulating a new hypertextual reality for comprehending the world), is taken here for granted. The other side of the matter, that this new model of space, developed as an optical science on strict mathematical groundwork, had mesmerized the artists and had hovered over their minds in a manner of dimming the border between art and science, has been given ample evidence by Martin Kemp (1990; see also Damisch, 1995, p. 11; Speer, 1994, p. 965; Tuve, 1968, p. 272).

2 See Physics 212a27f.: "So it appears that place is a surface-continent that embraces its content after the fashion of a vessel. [...] It follows that if a body is encompassed by another body, external to it, it is 'in a place'; but if not, not." Thus, Max Jammer concludes, Aristotle's space is a "sum total of all places occupied by bodies, and 'place' (topos), conversely, is conceived as that part of space whose limits coincide with the limits of the occupying body" (Jammer, 1954, p. 15). Plato's more mathematical disposition had set him to interpret space as material continuum consisting of different geometrical forms (icosahedron, octahedron, pyramid, cube) basing the reality of different elements (water, air, fire, earth). Of course, the relying on bodies in Platonic-Aristotelian tradition should not make us blind to the different concepts of space held (e.g., by atomists and Stoics) in antiquity as well.

For the corporeality of space in ancient aesthetics and Platonic-Aristotelian thinking, see Gadamer, 1999, pp. 277-279; Panofsky, 1997, p. 41; Grant, 1981, pp. 5-8; Čapek, 1976; Lossev, 1963, p. 289. The formative role of body in the some essential concepts of Renaissance art has been highlighted by Zwijnenberg, 2003, p. 175; Puttfarken, 2000, pp. 124ff.; Kölmel, 1998; Panofsky, 1997, p. 67; 1966, pp. 9ff.; Summers, 1977, p. 65. 
ancients' disgust with infinity and their abstinence from the idea of void as meaningless and incomprehensible can be regarded as belonging to the same battery of ideas (Maor, 1987, p. 3 et al.). To put it still in another way, the pretension of setting up the concept of space as existing separately from bodies was not rated very intelligible in the mainstream of ancient intellectual tradition. The situation underwent some radical changes in the milieu of Christianity. The monotheistic God of Christianity induced a strong investment in paradoxes and negative theology because he compelled thinking of a unified source behind worldly differences (see Carabine, 1995). This source, called God in Christianity, appropriated successfully and in its idiosyncratic way some arguments from Neoplatonism (Beierwaltes, 1998; O'Meara, 1982). An additional complexity was included in the Christian God because this monotheistic divinity appeared itself to have a triple personality, brought into view in the Trinitarian concept of Christendom (Atherton, 1976; Segal, 2001). A good example of the overturning of meanings ushered in by Christianity is the vindication of infinity as one of the substantial predicates of the Christian God (Mühlenberg, 1966; Sweeney, 1992). What had not been possible in the ancient polytheistic world had been accomplished effortlessly under the insignia of the Christian One-God (see also Undusk, 2009).

According to my argument, we should thus meet in the Renaissance a construction of space which, on the one hand, relies on bodies and their extensions, but which, on the other hand, provides this embodied space with certain transcendent clues that direct the viewer in his/her perception of the world to an abolition of the extended matter and of the spatial articulation offered by it. To refine the point, I would allege that while medieval thinking had posed the question about transcendent predicates, such as Infinite, or One and Truth, mainly in their relation to God (Grant, 2001, p. 230), the desire underpinning Renaissance scientific goals is to find out the possible equivalents of these divine predicates in our physical experience of the world. ${ }^{3}$ This desire grounds the essential cognitive dilemma of the Renaissance. Before going to the matter of the paper, I would wish to play up still another conceptual achievement from the Middle Ages. The import of the coupling of intuition and abstraction is known to everyone familiar with medieval philosophy. To explain the matter concisely and in broad lines: while intuition refers to the immediate existential grasp of something (that is, to something's being in actu) through seeing, abstraction operates on the level

\footnotetext{
The interpretation of medieval philosophy on the basis of its specific enhancement of the concept of transcendentality has been proposed and developed by Jan Aertsen in his various works (Aertsen, 1996; 2012). For the linking of transcendent with immanent in the Renaissance and modernity, see Blumenberg, 1996, pp. 202, 559ff.; Brient, 2002.
} 
of rationality without requiring that the object of cognition be present, that is, being seen (see Gauvard, Libera \& Zink, 2004, pp. 2-4, 724-726). The fact that I am today "here" allows me to say that I intuit the place here, that is, I know that it exists. Tomorrow, being in some other location, I can create myself an abstract knowledge about "my today's presence here" but I am not able anymore to intuit the place that had testified to my perception of existence yesterday, because, being disposed differently in the world, I cannot see it. Now, the great paradox to which the medieval philosophers felt themselves to be exposed, was the following: why is it that we need to abstract from the perception of presence, that is, from intuition, to come to the knowledge of things, when we still feel in our heart that there is a kind of perfection in the presence which becomes irretrievably lost in abstraction. Or, to put it differently, why do we know better about our today's presence tomorrow, if we still confess, being honest with ourselves, that there is an incontestable perfection in today which disappears tomorrow-despite all the gain in rationality. This is the question medieval thinking had to ponder, and the possible solution proposed by John Duns Scotus is highly significant: namely it was argued that the intellect, being superior to the senses, cannot lack the ability owned by lower cognitive powers, that is, there was suggested an idea of intellectual intuition, or of seeing by intellect in its own and higher way what was seen by the senses only on the physical level (Ordinatio IV, d. 45, q. 3; see also Libera, 1996, p. 324; Undusk, 2012, pp. 33ff.). The intellectual intuition, which promises rationality to experience in a much more ennobled way the same kind of immediacy as offered by the senses, takes us right to the Renaissance concept of space and to one of its authors, Nicholas of Cusa (see also Helander, 1988).

\section{The coupling of the finite with the transcendent in Nicholas of Cusa}

To explain what I had in my mind when I claimed that Renaissance space combines ancient finitism with transcendency, I will make use of one of Nicholas' favorite examples which he obtained from Meister Eckhart but which actually derives from the $12^{\text {th }}$ century pseudo-hermetic Liber viginti quattuor philosophorum (Book of 24 Philosophers, see Flasch, 2011). Namely, to demonstrate how divine infinity embraces all the differences of worldly reality in a unique and single way, Nicholas proposes that we imagine a sphere of infinite extension and, accordingly, sets us face to face with the following deductions. First, says Nicholas, just as the infinite sphere, extending its surface to endlessness, comes 
deprived of its definite centre, which has to be located in fact in every point inside the infinite sphere, so similarly is the Christian God infinite, with his circumference nowhere and his centre everywhere (De docta ignorantia I.23). Second, supposing that the sphere as a figure consists of curved lines and curved spaces, Nicholas sets us to infer that the curves of the sphere, being extended to infinity, should become more and more similar to their tangents, that is, the curved lines should approach straight ones and the curved spaces should become increasingly flat (De docta ignorantia I.13). And this feature of infinite sphere offers itself to Nicholas again as a splendid instance of divine unity. Reverting to my own line of thought, I state that by supplying the corporeal finite structure, be it sphere, triangle, or whatever, with clues to infinity at its borders, Nicholas invalidates the definition of body through extension, because, it is quite clear, the assimilation of different bodies in infinity occurs at the expense of their loss of meaning in terms of their measurability. Anyhow, keeping our target in view, we should ask, what has it all to do with Renaissance space? I will envisage here three answers to the question in shorthand. First, the definition of bodies through their unity in infinity represents, in my view, a decisive step away from the ancient topology towards space as autonomous reality that not only sustains things passively, by offering them a place to be, but cooperates directly in the definition of these things in our knowledge about them (Field, 1997, p. 227). The origin of the things in infinity provides them with an aspect substantial to our human intelligence. Second, the image of the infinite sphere, applied to the earth and universe, could be taken as instrumental in dismantling the geocentric picture of the universe and in pitching the discourse on humanity in a very different key of multiple stellar systems. (See Blumenberg, 1996, pp. 590-591.) This move should have meant a dramatic loss in dignity for the inhabitants of the earth. Anyhow, the decline in self-esteem, caused by decentralization of the cosmos, was refunded by the discovery of centrality in each individual point of the infinite universe.

As suggested already above, we can say that Nicholas of Cusa would not have been an excellent Renaissance man if he had not wished his rich elaborations on infinity and on coincidentia oppositorum to have said anything about physical nature and our experience of it. The example of the infinite sphere discloses the geometrical and mathematical undergirding of his thinking (Flasch, 2008, pp. 171ff., 392ff.). Now, the clues to infinity, which Nicholas sets onto his mathematical figures and which intimate them as contracting to a point or enlarging to endlessness, are not only marks of mixing up transcendency with corporeal finitism, but they carry in themselves as well the medieval profound 
desire to reach a kind of seeing of God, that is, to reach the intellectual intuition where physical reality is perceived in visual immediacy but, at the same time, as originating directly from the unity of God. The fact is proven by Nicholas' abundant use of visual metaphor in his discussion of godly infinity as well as by his work De visione dei, where God's look, seeing all and everywhere, grounds, in fact, the whole visual experience of the world. (See Flasch, 2008, pp. 383-443.) In this sense, the clues to infinity conduce not only to the equivalence of a curved and a straight line, but they cooperate as well in Nicholas' intention to propose a theory of visuality in which infinity possesses a strategic role, being at once a unifier of worldly things and a source of their visuality. I would claim that the idea of intellectual intuition, which had been coupled in medieval context to the talk about the possibility of seeing God, becomes under the pen of Nicholas an element of his geometrical elucidation of the world. Arguing that infinity is included in our every act of visual experience, ${ }^{4}$ Nicholas is, in fact, intimating that if we could integrate this infinite into our geometrical representation of visual forms, we could intellectualize our seeing to the degree where tomorrow's grasp of today's presence is at once more comprehensive and more immediate than the presence offered us today by our senses. At this point we are coming close to the second item of this paper because the Renaissance search for a new spatial configuration begot as its by-product a special type of fictional space in Renaissance art.

\section{The accommodation of infinity in Renaissance painting}

It has been said that the geometry of modern ages was in a certain sense born out of art, or more exactly, out of Renaissance painting (Damisch, 1995, p. 83; Field, 1997). We could add that the Renaissance entanglement of two types of inspiration, of the scientific and of the artistic kind, relied on some significant peculiarities of the epoch. First, although there existed a powerful drive, mainly of theological origin, to inscribe infinity into the geometrical and spatial structures of thinking, the concept of infinity was to remain without strict mathematical content still for centuries. It means, though, that the mathematical appropriation

\footnotetext{
4 See, for example, De visione dei VIII.32 and IX.37: "Moreover, the angle of Your eye is a circle—or better, an infinite sphere-because Your sight is an eye of sphericity and of infinite perfection. Therefore, Your sight sees—-roundabout and above and below—all things at once. [...] If, then, Your essence penetrates all things, then so too does Your sight, which is Your essence. Therefore, just as none of all existing things can escape from its own being, so neither can it escape from Your essence, which gives to all things their essential being." (Quoted in Hopkins, 1988, pp. 153, 157.)
} 
of infinity as God's attribute was to proceed in the Renaissance largely on nonscientific ground, or on the ground of some inexplicable sensuous experience, which in its turn means that a door was opened for effective collaboration between artistic representation and scientific knowledge.

The second characteristic of the Renaissance should explain the matter even better. Renaissance painting has been held to be the author, in the sense of bringing to completion, of linear perspective as a way of envisioning the world. This mode of visual representation, being remarkable for its voluminous spatial capacity, is based, in fact, on exact mathematical calculation, which prescribes how things on canvas should be reduced from foreground to background to invoke a specific illusion of space. Recalling, for example, the paved floors of early Netherlandish paintings, where all the slabs diminish according to distance and where all horizontal lines tend to converge at a point in the background, should exemplify in a simple way the essence of the matter. Now, what interests us here is the fact that linear perspective operates, in fact, with two kinds of elements: with lines that possess extension and with points that are in the mathematical sense extensionless. Furthermore, in postulating that all horizontally running parallel lines should be represented on the picture plane as tending to converge at a certain remote point, linear perspective makes, in fact, the visibility of a picture to originate from the non-visibility of a point. The wording I use here should appear to be quite similar to the one I employed previously in talking about Nicholas' search for the equivalents of transcendency in our experience of nature. The appearance is solidified into more constant reality by the fact that the first Renaissance theory of perspective, contained in Leon Battista Alberti's De pictura (1435, the Italian version Della pittura 1436) ${ }^{5}$, actually uses the word "infinity" to denote the converging point of parallel lines. ${ }^{6}$ If so, we should ask, can we not say that linear perspective is proposing an actual theory of visual representation which turns Nicholas' philosophical precepts into practical advice for artists and geometers. I believe the statement is quite tenable, but at the same time I am far from pretending to have said with this something new or ground-breaking. Rather, the knowledge enclosed in the statement belongs to the lore of Renaissance scholarship. My real aim is to make clear that in transforming Nicholas' attempted combination of corporeal finitism with transcendency into a practical theory of art, Renaissance painters were doing something that they really did not understand themselves to have been doing.

\footnotetext{
A suggestion that Alberti actually wrote his book first in the vernacular and only after that composed a Latin version, has been made by Rocco Sinisgall; see Alberti, 2011, pp. 3-14.

6 "Having placed the centric point, I draw straight lines from it to each of the divisions on the base line. These lines show me how successive transverse quantities visually change to an almost infinite distance [paene usque ad infinitam distantiam ...alterentur ]." (Alberti, 1991, p. 54)
} 
There has been a discussion, especially in relation to linear perspective, about the subjective nature of every illusion of reality (e.g., Gombrich, 1977; see also Grootenboer, 2005). Thus, it has been argued, Renaissance perspective painting should not impress with its reality effect in every cultural context. I would wish to avoid the discussion here and to cling simply to two testimonies verifying a certain realistic underlay of perspective fictionality. First, there exists some historical information proving that when Filippo Brunelleschi painted, at the beginning of the $15^{\text {th }}$ century, his two panels of two of Florence's buildings, which are supposed to be the first examples of correct mathematical use of linear perspective, he and his friends were exactly impressed by the deep effect of reality produced by the pictures, especially when they were looked at in a mirror set in front of the panel, while the viewer himself stood behind the picture and looked through a little hole made into the proper place of the panel. ${ }^{7}$ Set all at the right distance, the viewer experienced an enchanting illusion of reality while looking to infinity where he, in fact, came across his own eye. Second, whatever the relation of perspective painting to the perception of reality may have been, the fact is that linear perspective aimed at a kind of correct mathematical rendition of physical space and was in this sense surely endowed with a streak of realism in its nature. The kernel of my argument is, though, that in creating an optical illusion of three-dimensional space on a two-dimensional plane, the Renaissance artists started not from actual but from aesthetic reality, that is, they were fascinated by the effect produced by the subjection of any measurable quantity to the immeasurable point at infinity, being at the same time not ready to offer an explanation of this visual experience. Hubert Damisch, who has thoroughly studied the topic, says that Renaissance artists were in fact scared of the infinite point as an illogical and incomprehensible element of a picture, and, accordingly, preferred to cover it up, or to hide it by opening a prospect of landscape or a sight of heaven (Damisch, 2002, pp. 163-165). The infinity at the focus of the picture should have presented itself to Renaissance artists in a really triggering way. Linear perspective could be said to be a very logical and mathematically exact system of spatial representation until the point which supposes that parallels meet and all measurability loses its meaning. This assumption possessed no rationale in the Renaissance and was actually at variance with the Euclidean geometry obtaining

\footnotetext{
A historical testimony to Brunelleschi's invention of mathematical rules for perspective and to his two panels (of the Baptistry of San Giovanni and of Palazzo della Signoria), evincing the application of these rules, is given by Antonio Manetti in his Brunelleschi biography, Vita di Brunelleschi, compiled, indeed, in the 1480 s. As to the illusion of reality felt by the spectator at the face of the paintings, Manetti's comment is: "With the aforementioned elements of the burnished silver, the piazza, the viewpoint, etc., the spectator felt he saw the actual scene when he looked at the painting. I have had it in my hands and seen it many times in my days and can testify to it." (Manetti, 1970, p. 44)
} 
at that time. Curiously enough, the whole system of perspective representation came to depend on this subversive detail which made, in a strange way, the picture very reality-like. By this consideration I have come to the last point of the paper and shall try to sketch briefly how the Renaissance fictional picture plane possibly participated in the production of new knowledge about real spaces.

\section{Renaissance painting and modern geometry}

There exists some evidential basis to suggest an intellectual linkage between the more or less experiential inventions of Renaissance painters and the ideas that led to substantial insights of modern geometry, including projective geometry and non-Euclidean geometries of the $19^{\text {th }}$ century. The fifth postulate of Euclid's Elements, or the so-called parallel postulate, can be viewed as a linchpin of the process that exposed also a definite essay to pin down the irrationality of the infinite at which the Renaissance artists had baulked. When Girard Desargues had formulated in 1639 in his Brouillon project (Rough Draft of Attaining the Outcome of Intersecting a Cone with a Plane) some fundamental principles of the later projective geometry, and in doing this was, according to Field, "the first mathematician to get the idea of infinity under control” (Field, 1997, p. 196), he was most obviously developing some ideas that had latched onto his mind already three years earlier in his short treatise on drawing in perspective (Field, 1997, pp. 192ff.; Damisch, 1995, p. 387). Awakened into new life by Jean Poncelet and others some two hundred years later, the implications of Desargues' theorem revealed having not only a dissenting power to breach the frontiers of incumbent geometry - by their testifying to the mathematical sense of parallels meeting at infinity-, but the new perspective disclosed by projective geometry proved to be also extremely inclusive because its capacity was to hold the raison d'être of all possible geometries, of Euclidean as well as of non-Euclidean. This possible universality was hinted at already by the title of Nikolay Lobachevsky's last work, Pangéométrie $(1855)^{8}$, but it was shown later by Arthur Cayley and Felix Klein to be strictly derivative from the genius of projective (descriptive) geometry. ${ }^{9}$ Thus, if we can suppose an artistic impetus of perspective drawing at the origin of some of the most comprehensive

For Lobachevsky's usage of "pangeometry", see Papadopoulos, 2010, pp. 230-231.

9 A succinct formulation of the truth arrived at was given by Cayley in his Sixth Memoir in 1859: "Metrical geometry is thus a part of descriptive geometry, and descriptive geometry is all geometry and reciprocally..." (Cayley, 1859, p. 90). A further elaboration of the idea was offered by Klein in his treatises Über die sogenannte nicht-euklidische Geometrie (I-II, 1871-1873). About the development of the idea, see Klein, 1926, pp. 147-155; Gosztonyi, 1976, pp. 525-531; also Jammer, 1954, pp. $156 f f$. 
ideas of modern geometry, which set up a system for the continuous production of most various types of spatial modifications, we will have an implicit, indeed very indirect, testimony to the transformation of planar artistic illusion of Renaissance space into knowledge about modern real spaces.

I would like to conjure up here some elementary images to hazard a guess as to what the Renaissance painters could have been performing in their pictures from the viewpoint, for example, of the modern non-Euclidean geometry. As we know, the difference between Euclidean and non-Euclidean geometries is not so thorough as suggested by the words themselves. In fact, the difference results only from the non-Euclideans' setting a ban on Euclid's fifth or parallel postulate, which means, to put it very simply, that while Euclideans assert parallels to remain at the same distance from each other everywhere in space, the non-Euclideans maintain that parallels can either approach each other (elliptic geometry) or diverge from each other (hyperbolic geometry); that is, they testify to the possibility of convergence of parallel lines in reality, and not in mysterious "infinity". To couch in the same simple manner an explanation of this postulated truth, we need, in fact, only to take a quick look at a globewitness that the meridians crossing the equator all at the right angles (and being accordingly parallels) meet at two places at the poles, at the North and at the South. The only substitution we have to make in our minds, to fill this evident visual experience with content from the viewpoint of the theory of relativity, is to say that it is not the earth as a celestial body which makes parallels to curve and to meet, but that it is the force of gravitation permeating space which causes the universe to possess a curved character. The message conveyed by non-Euclideans is that the description of bodies is not attainable solely on the grounds of their metrical characteristics apart from the physical conditions in which the bodies are situated (see Jammer, 1954, p. 144). Accordingly, space and spatial qualities could not be said to be determined and articulated simply by metrics of bodies, because the bodies themselves suffer from the impact of space which, so to say, deforms permanently the bodies' readability in terms of extensionality. The idea has got a clear expression by Albert Einstein who states in his theory of relativity that "there exist no completely rigid bodies. All bodies are elastically deformable and alter in volume with change in temperature. The structures, whose possible congruences are to be described by Euclidean geometry, cannot therefore be represented apart from physical concepts." (Einstein, 2002, p. 146)

How could this kind of considerations assist us in figuring out a possible answer to the actions conducted, for example, by a perspective painter in his representation 
of the world? I believe that we are quite right if we allege that in the sense of his available field of activity every painter is a kind of flatlander who attempts, inasmuch as he does it, to bring onto the plane of the picture an image of the tridimensional experiential space. Now, let us assume for the sake of argument that our painter, who is a flatlander by his means of artistic articulation, is a person who has passed in his mind a thorough training in non-Euclidean geometry as well as in the general theory of relativity, and is disposed to believe, for example, that our universe is shaped according to elliptic geometry as a spherical space. In trying to convey an image of his mental understanding of the shape of the universe, he is supposedly forced, because of being dispossessed of any means on his worktable to build a representation of three-dimensional curvature, to resort to the same kind of structure of meeting parallels (meridians) as practiced by the Renaissance painter, with the single qualification that our painter, contrary to his Renaissance peer, realizes perfectly well that the ghastly infinity in his picture is nothing more than a point where the parallels are just accomplishing a turn back to his occiput. The evident objection to this kind of presentation of the matter would very reasonably be that the portion of the universe grasped by any Renaissance painter, inasmuch as he is depicting the earthly substance, is ineligibly small to allow any induction in the vein of non-Euclidean theory of space. Conceding the absolute relevance of this counter-argument from the point of view of physics, it loses much of its weight if we acknowledge the very probable religious contour of the Renaissance perspective method and, accordingly, consider the act of setting the parallels to meet in infinity as a way of bringing (in Cusanist mode) God's sight into however small a section of the world. As it is quite clear that God can see nothing less than a universe, we can say that a universe is included necessarily in every perspective picture, even if the portion of the universe represented there is, say, only some tiny part of a dining room. From the point of view of our flatlander who is well versed in elliptic geometry, the Renaissance painter can be interpreted as stretching his mental image, every time he sets the things on canvas to correct perspective relationship, over the spherical universe to make then a flat copy of it-not because the Renaissance man knows that God is a universe of elliptic nature, but because in acting so he believes to be obtaining some amazing reality effect for human eyes, which, in addition (wow!), is undergirded by God's sight itself.

Even if my suggestion about the Renaissance painter as a flatlander paying in his blissful ignorance some backhanded compliments to modern geometers is a conjecture without basis, I still wish to insist here, as to my conviction, on the "topological" continuity in culture between the distinct expositions of reality. As the personal truths should become, if we are to achieve any comprehensive 
meaning of human culture, translatable, instead of being mutually exclusive, there exists, I believe, a cooperation in the production of meaning between religious imagery, artistic or aesthetic veracity, and systematic knowledge, which, true, exceeds any disciplinary boundaries for investigation but assumes beneficently an existence of a transformative formula between the respective topologies adopted. Without doubt, the flatlander can in his own "defective" way come to know something about elliptic geometry even before the man of three-dimensional space has an inkling of it; as the man of Euclidean schooling can, by the mercy of God and being confronted with some mesmerizing effect of aesthetic illusion, start to indicate non-Euclidean truths (which later will not only be secularized as parts of some axiomatic geometry but will be proven as well to be relevant to the real physical spaces - the "real" having now reference to the science and not the effectiveness of visual perception). The increment of knowledge goes, I believe, not so much by addition as by the recognition of some former subconscious aspect of the subject traversing some new spatial configuration.

For the time being, however, let us state that the certain complementarity of modern painter and geometer is not restricted to their affinity in inspiration (both grappling with the parallel axiom) nor to the fact that the universalist concept elaborated by projective geometry had in the Renaissance a kind of correlate in the theory of divine vision as a possible stimulus for reasoning on painting. Both, the painter and the geometer, struggled as well in their own way with what we can call a metrical grasp of things. There exists an attestable effort on the part of painters, for example, to move the definitive basis of reality from line to the illuminative interaction of bodies and, accordingly, to link the geometrical representation of bodies to the disclosure of their inner dynamical potential (Damisch, 2002, pp. 135-139, 157-163). Leonardo's works, especially his last ones, Visions of the End of the World, offer us an expressive testimony to the capturing of nature as natura naturans. As parallel to this artistic plunge into the elemental war, let us note that the achievement of projective geometry rested very much on its introduction into geometry of the concept of incidence as a contrary term to all these geometrical properties that can be expressed in metrical terms (such as angle, distance, and so on). As a result, geometry obtained its ability to describe the properties of figures that are not altered in mappings and projective transformations, or, to bring things back to our train of thought, it learned how to conceive of the figures as though in process-outside the strict metrical characters pertaining to them as rigid bodies. In this sense, the modern painter and geometer had, even if the parallel drawn here stands on a bit elliptic ground, quite the same thing in mind. 


\section{Acknowledgements}

The study has been financed by the institutional research funding project 'Entangled Literatures: Discursive History of Literary Culture in Estonia' (IUT28-1).

I am thankful to the anonymous referees for their valuable comments and suggestions, which helped to bring the article to completion.

\section{References}

Aertsen, J. A. (1996), Medieval Philosophy and the Transcendentals: The Case of Thomas Aquinas, Studien und Texte zur Geistesgeschichte des Mittelalters, vol. 52, Leiden \& Boston: Brill.

- (2012), Medieval Philosophy as Transcendental Thought. From Philip the Chancellor (ca. 1225) to Francesco Suárez, Studien und Texte zur Geistesgeschichte des Mittelalters, vol. 107, Leiden \& Boston: Brill.

Alberti, L. B. (1991), On Painting, transl. by C. Grayson, with an introduction and notes by M. Kemp, Harmondsworth: Penguin Books. http://dx.doi.org/10.1017/ CBO9780511782190

— (2011), On Painting: A New Translation and Critical Edition, ed. and transl. by Rocco Sinisgall, Cambridge: Cambridge University Press.

Atherton, P. J. (1976), “The Neoplatonic 'One' and the Trinitarian 'APXH'”, in B. Harris \& R. Baine (eds.) The Significance of Neoplatonism, Norfolk, VA: International Society for Neoplatonic Studies, pp. 173-185.

Beierwaltes, W. (1998), Platonismus im Christentum, Frankfurt am Main: Vittorio Klostermann.

Blumenberg, H. (1996), Die Legitimität der Neuzeit, erneuerte Ausgabe, Suhrkamp taschenbuch wissenschaft, vol. 1268, Frankfurt am Main: Suhrkamp.

Brient, E. (2002), The Immanence of the Infinite: Hans Blumenberg and the Threshold to Modernity, Washington: The Catholic University of America Press.

Čapek, M., ed. (1976), The Concepts of Space and Time: Their Structure and Their Development, Boston Studies in the Philosophy of Science, vol. 22, Dordrecht \& Boston: Reidel. http://dx.doi.org/10.1007/978-94-010-1727-5_72

Carabine, D. (1995), The Unknown God: Negative Theology in the Platonic Tradition. Plato to Eriugena, Louvain: W. B. Eerdmans. 
Cayley, A. (1859), 'A Sixth Memoir upon Quantics,' Philosophical Transactions of the Royal Society of London, vol. 149, pp. 61-90. http://dx.doi.org/10.1098/rstl.1859.0004

Damisch, H. (1995), The Origin of Perspective, transl. by J. Goodman, Cambridge, MA \& London: MIT Press.

_ (2002), A Theory of /Cloud/: Toward a History of Painting, transl. by J. Lloyd, Stanford: Stanford University Press.

Einstein, A. (2002), Relativity: The Special and the General Theory, authorised translation by R. W. Lawson, London \& New York: Routledge.

Field, J. V. (1997), The Invention of Infinity: Mathematics and Art in the Renaissance, Oxford, New York \& Tokyo: Oxford University Press.

Flasch, K. (2008), Nikolaus von Kues: Geschichte einer Entwicklung. Vorlesungen zur Einführung in seine Philosophie, Sonderausgabe, 3. Aufl., Klostermann Rote Reihe, vol. 27, Frankfurt am Main: Vittorio Klostermann.

— (2011), Was ist Gott? Das Buch der 24 Philosophen, Lateinisch-Deutsch, erstmals übersetzt und kommentiert von K. Flasch, München: C. H. Beck.

Gadamer, H.-G. (1999), 'Antike Atomtheorie' in H.-G. Gadamer, Griechische Philosophie I, Gesammelte Werke 5, Tübingen: J. C. B. Mohr, pp. 263-279.

Gauvard, C.; Libera, A. de \& Zink, M., eds. (2004), Dictionnaire du Moyen Âge, Quadrige. Dicos poche, $2^{\mathrm{e}}$ edition, Paris: Presses universitaires de France.

Gombrich, E. H. (1977), 'Ambiguities of the Third Dimension,' in Art \& Illusion. A Study in the Psychology of Pictorial Representation, 5th ed., London: Phaidon, pp. 204-244.

Gosztonyi, A. (1976), Der Raum: Geschichte seiner Probleme in Philosophie und Wissenschaften, Band 1, Freiburg \& München: Verlag Karl Alber.

Grant, E. (2001), God and Reason in the Middle Ages, Cambridge: Cambridge University Press. http://dx.doi.org/10.1017/CBO9780511512155

Grootenboer, H. (2005), The Rhetoric of Perspective. Realism and Illusionism in Seventeenth-Century Dutch Still-Life Painting, Chicago \& London: The University of Chicago Press.

Helander, B. (1988), Die visio intellectualis als Erkenntnisweg und-ziel des Nicolaus Cusanus, Studia Doctrinae Christianae Upsaliensia, vol. 29, Uppsala: Uppsala University.

Hopkins, J. (1988), Nicholas of Cusa's Dialectical Mysticism. Text, Translation and Interpretative Study of De visione dei, 2nd ed., Minneapolis: The Arthur J. Banning Press.

Jammer, M. (1954). Concepts of Space. The History of Theories of Space in Physics, foreword by A. Einstein, Cambridge, MA: Harvard University Press.

Kemp, M. (1990), The Science of Art: Optical Themes in Western Art from Brunelleschi to Seurat, New Haven \& London: Yale University Press.

Klein, F. (1926), Vorlesungen über die Entwicklung der Mathematik im 19. Jahrhundert, Teil I, Berlin: Verlag von Julius Springer. 
Kölmel, W. (1998), 'Roger Bacon: Körper und Bild,' in J. Aertsen \& A. Speer (eds.) Raum und Raumvorstellungen im Mittelalter, Miscellanea Mediaevalia, vol. 25, Berlin \& New York: Walter de Gruyter, pp. 729-738. http://dx.doi. org/10.1515/9783110802054.729

Kristeller, P. O. (1990), Renaissance Thought and the Arts. Collected Essays, Princeton, NJ: Princeton University Press.

Libera, A. de (1996), La querelle des universaux. De Platon á la fin du Moyen Age, Paris: Seuil.

Lossev, A. (1963), Istoriia antichnoi estetiki (rannyaya klassika), Moscow: Vyshaya shkola.

Manetti, A. (1970), The Life of Brunelleschi, introduction, notes and critical text edition by H. Saalman, transl. by C. Enggass, University Park: Pennsylvania State University Press.

Maor, E. (1987), To Infinity and Beyond: A Cultural History of the Infinite, Boston: Birkhäuser. http://dx.doi.org/10.1007/978-1-4612-5394-5_10

Mühlenberg, E. (1966), Die Unendlichkeit Gottes bei Gregor von Nyssa: Gregors Kritik am Gottesbegriff der klassischen Metaphysik, Göttingen: Vandenhoeck \& Ruprecht.

O'Meara, D. J., ed. (1982), Neoplatonism and Christian Thought, Studies in Neoplatonism: Ancient and Modern, vol. 3, Albany, NY: State University of New York Press.

Panofsky, E. (1966), Early Netherlandish Painting: Its Origins and Character, vol. 1, Cambridge, MA: Harvard University Press.

- (1997), Perspective as Symbolic Form, transl. by C. S. Wood, New York: Zone Books.

Papadopoulos, A. (2010), 'A commentary on Lobachevsky's Pangeometry', in N. Lobachevsky, Pangeometry, ed. and transl. by A. Papadopoulos, Zürich: European Mathematical Society, pp. 227-298. http://dx.doi.org/10.4171/087

Puttfarken, T. (2000), The Discovery of Pictorial Composition: Theories of Visual Order in Painting 1400-1800, New Haven \& London: Yale University Press.

Segal, A. F. (2001), “'Two Powers in Heaven' and Early Christian Trinitarian Thinking," in S. T. Davis, D. Kendall \& G. O'Collins (eds.) The Trinity: An Interdisciplinary Symposium on the Trinity, Oxford: Oxford University Press, pp. 73-95.

Speer, A. (1994), 'Kunst und Schönheit. Kritische Überlegungen zur mittelalterlichen Ästhetik,' in I. Craemer-Ruegenberg \& A. Speer (eds.) Scientia und ars im Hoch-und Spätmittelalter, Miscellanea Mediaevalia vol. 22.2. Halbband, Berlin \& New York: Walter de Gruyter, pp. 945-966.

Summers, D. (1977), 'Figure come Fratelli: A Transformation of Symmetry in Renaissance Painting,' Art Quarterly, vol. 40, no. 1, pp. 59-88.

Sweeney, L. J. (1992), Divine Infinity in Greek and Medieval Thought, New York: Peter Lang.

Tuve, R. (1968), 'Imagery and Logic: Ramus and Metaphysical Poets,' in P. O. Kristeller \& P. H. Wiener (eds.) Renaissance Essays, New York \& Evanston: Harper \& Row, pp. 267-302. 
Undusk, R. (2009), 'Infinity on the Threshold of Christianity: The Emergence of a Positive Concept out of Negativity,' Trames, vol. 13, no. 4, pp. 307-340. http://dx.doi.org/10.3176/tr.2009.4.01

(2012), 'Faith and Reason: Charting the Medieval Concept of the Infinite,' Trames, vol. 16, no. 1, pp. 3-45.

Zwijnenberg, R. (2003), 'Why Did Alberti not Illustrate his De Pictura?' in S. Gersh \& B. Roest (eds.) Medieval and Renaissance Humanism. Rhetoric, Representation and Reform, Brill's Studies in Intellectual History, vol. 115, London \& Boston: Brill, pp. 167-184. http://dx.doi.org/10.1163/9789047402619_009

Rein Undusk obtained his MA in Estonian philology from the University of Tartu in 2001. At present he is a researcher in the rhetorics of culture at the Under and Tuglas Literature Centre of the Estonian Academy Sciences. His main interests have been focused on the theoretical and rhetorical aspects of textual analysis. He is currently studying the concept of the infinite in the history of thinking, with special interest on the relationships between sensibility, intellection, and transcendency in culture. 